\title{
Influences of the Atlantic Warm Pool on Western Hemisphere Summer Rainfall and Atlantic Hurricanes
}

\author{
Chunzai Wang and David B. Enfield \\ Physical Oceanography Division, NOAA/Atlantic Oceanographic and Meteorological Laboratory, Miami, Florida \\ SANG-KI LEE \\ Cooperative Institute for Marine and Atmospheric Studies, University of Miami, Miami, Florida \\ CHRISTOPHER W. LANDSEA \\ NOAA/National Hurricane Center, Miami, Florida
}

(Manuscript received 4 February 2005, in final form 13 October 2005)

\begin{abstract}
The Atlantic warm pool (AWP) of water warmer than $28.5^{\circ} \mathrm{C}$ comprises the Gulf of Mexico, the Caribbean Sea, and the western tropical North Atlantic (TNA). The AWP reaches its maximum size around September, with large AWPs being almost 3 times larger than small ones. Although ENSO teleconnections are influential on the AWP, about two-thirds of the large and small AWP variability appears unrelated to ENSO. The AWP is usually geographically different from the TNA; however, the AWP size is correlated with the TNA SST anomalies. During August to October, large AWPs and warm TNA are associated with increased rainfall over the Caribbean, Mexico, the eastern subtropical Atlantic, and the southeast Pacific, and decreased rainfall in the northwest United States, Great Plains, and eastern South America. In particular, rainfall in the Caribbean, Central America, and eastern South America from August to October is mainly related to the size of the AWP. Large (small) AWPs and warm (cold) TNA correspond to a weakening (strengthening) of the northward surface winds from the AWP to the Great Plains that disfavors (favors) moisture transport for rainfall over the Great Plains. On the other hand, large (small) AWPs and warm (cold) TNA strengthen (weaken) the summer regional Atlantic Hadley circulation that emanates from the warm pool region into the southeast Pacific, changing the subsidence over the southeast Pacific and thus the stratus cloud and drizzle there. The large AWP, associated with a decrease in sea level pressure and an increase in atmospheric convection and cloudiness, corresponds to a weak tropospheric vertical wind shear and a deep warm upper ocean, and thus increases Atlantic hurricane activity.
\end{abstract}

\section{Introduction}

The El Niño-Southern Oscillation (ENSO) affects precipitation variations over the globe (e.g., Ropelewski and Halpert 1987, 1989; Diaz et al. 2001). When ENSO sea surface temperature (SST) anomalies in the equatorial eastern Pacific reach their maximum around November-December, the heat source of the IndoPacific warm pool shifts eastward and alters atmospheric convective activity leading to ENSO teleconnections on a global scale. Figure 1a shows a Western

Corresponding author address: Dr. Chunzai Wang, Physical Oceanography Division, NOAA/Atlantic Oceanographic and Meteorological Laboratory, 4301 Rickenbacker Causeway, Miami, FL 33149.

E-mail: Chunzai.Wang@noaa.gov
Hemisphere (WH) map of the correlation of December-February (DJF) rainfall anomalies with the DJF Niño-3 $\left(5^{\circ} \mathrm{S}-5^{\circ} \mathrm{N}, 150^{\circ}-90^{\circ} \mathrm{W}\right) \mathrm{SST}$ anomalies (see section 2 for detail in data and calculation). A major feature for ENSO-related winter rainfall is an oppositely signed rainfall correlation pattern over a long latitudinal band, with positive correlation from the subtropical North Atlantic to the western United States and negative correlation from northern South America to north of the equatorial Atlantic (as well as over Northeast Brazil). A transition zone separating the positive and negative rainfall correlations is located around $18^{\circ}-$ $20^{\circ} \mathrm{N}$.

During the boreal summer, however, either in the development/decay phases of El Niño or during neutral conditions, equatorial eastern Pacific SST anomalies are relatively weak and ENSO teleconnections are 

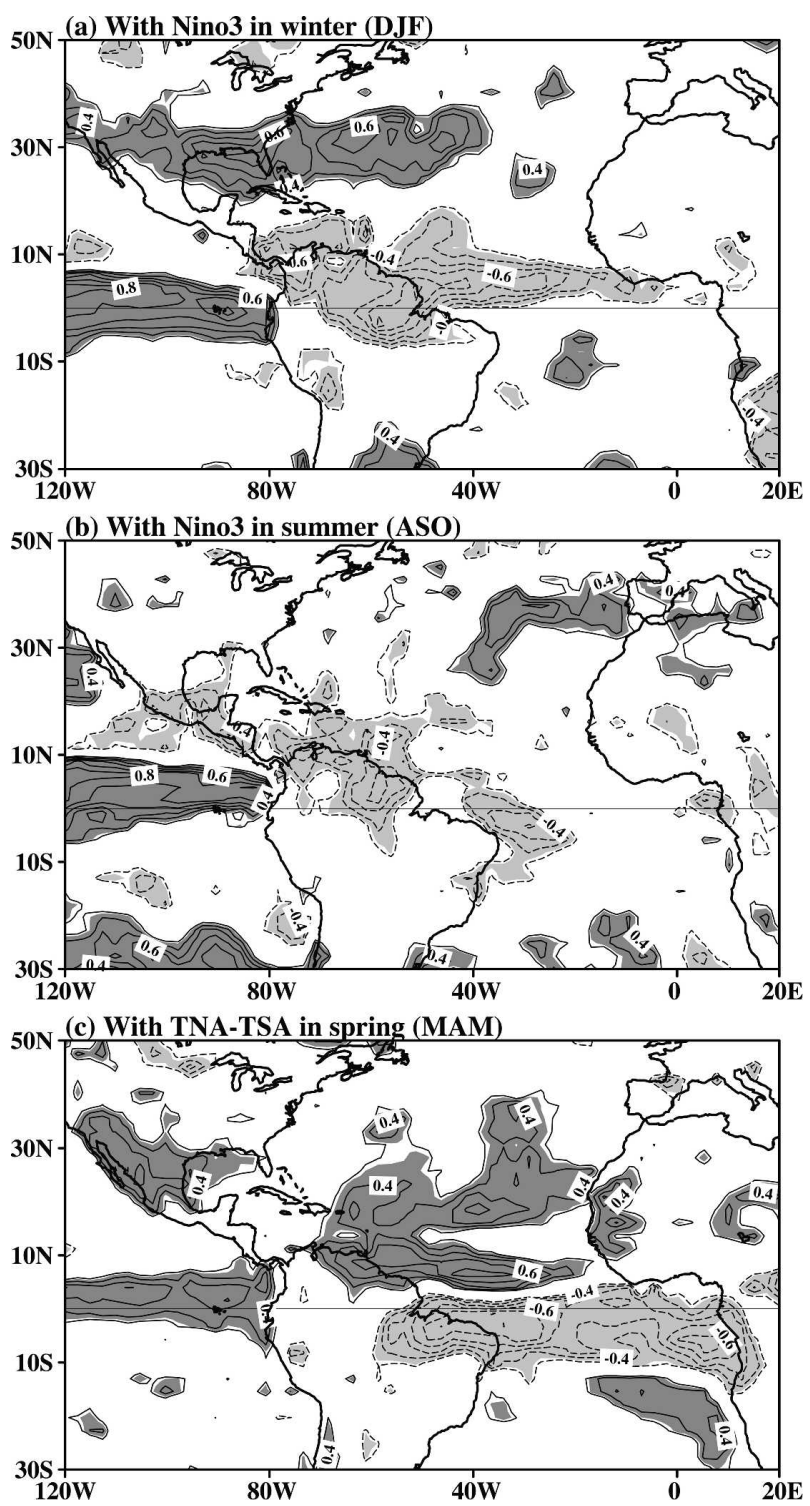

FIG. 1. (a) Correlation of DJF rainfall anomalies with the DJF Niño-3 SST anomalies, (b) correlation of ASO rainfall anomalies with the ASO Niño-3 SST anomalies, and (c) correlation of MAM rainfall anomalies with the MAM SST anomaly difference between the TNA and TSA. The contour interval is 0.1 and the correlations below \pm 0.3 are not plotted. The $90 \%$ and $95 \%$ significant levels are 0.33 and 0.39 , respectively. The shadings represent correlation larger than 0.33 (dark for positive and light dark for negative).

different from those in the boreal winter (Alexander et al. 2004). Figure $1 \mathrm{~b}$ displays the correlation map of August-October (ASO) rainfall anomalies with the ASO Niño-3 SST anomalies. During ASO, the northern band of positive rainfall correlation disappears. In fact, Fig. $1 \mathrm{~b}$ agrees with some studies that a negative correlation exists over the Caribbean and Central America (e.g., Enfield and Alfaro 1999; Giannini et al. 2000; Diaz et al. 2001; Chen and Taylor 2002; Taylor et al. 2002; Spence et al. 2004) and in northern South America and the western equatorial Atlantic (Fig. 1b).

Tropical Atlantic variability also affects Western Hemisphere (WH) rainfall (e.g., Moura and Shukla 1981; Folland et al. 1986; Enfield 1996; Giannini et al. 2000; Taylor et al. 2002; Spence et al. 2004). One of the important tropical Atlantic climate phenomena is the tropical Atlantic meridional gradient variability that is defined by the SST anomaly difference between the tropical North Atlantic (TNA: $6^{\circ}-22^{\circ} \mathrm{N}, 60^{\circ}-15^{\circ} \mathrm{W}$ ) and the tropical South Atlantic (TSA: $0^{\circ}-20^{\circ} \mathrm{S}, 30^{\circ} \mathrm{W}-$ $\left.10^{\circ} \mathrm{E}\right)$. This Atlantic meridional SST gradient variability, correlated with ENSO (e.g., Chiang et al. 2002; Xie and Carton 2004) and the north-south displacement of the Atlantic intertropical convergence zone (ITCZ), has maximum variance during the boreal spring. Its impact on spring [March to May (MAM)] rainfall in the WH is shown in Fig. 1c. The rainfall correlation patterns display an antisymmetric distribution over the TNA and TSA. Moura and Shukla (1981) showed an antisymmetric distribution of gridded SST anomalies correlated with Northeast Brazil rainfall although the TNA and TSA SST anomalies are mostly independent (e.g., Houghton and Tourre 1992; Enfield and Mayer 1997; Mehta 1998; Enfield et al. 1999; Dommenget and Latif 2000; Wang 2002; Melice and Servain 2003). The significant rainfall correlations extend over the surrounding land regions, with negative correlation over Northeast Brazil and positive correlation for northwest Africa and the northern part of South America. Enfield (1996) discusses the relationships of inter-American rainfall (all seasons) with the TNA, the TSA, and the Atlantic ITCZ.

Another tropical Atlantic climate phenomenon is the Atlantic warm pool (AWP) that occupies the Gulf of Mexico, the Caribbean Sea, and the western TNA (see section 3). The size of the AWP reaches its maximum in the boreal late summer. Unlike the Pacific El Niño and the tropical Atlantic meridional gradient variability, the rainfall distribution associated with the AWP is unknown. Given the fact that the dominant effects of the Pacific El Niño and the tropical Atlantic meridional gradient variability on rainfall are in the boreal winter and spring, respectively, it is not surprising that the AWP plays some roles in summer rainfall distributions in its surrounding regions. In this paper we report observational evidence of direct relationships between rainfall and the AWP during the boreal summer when its size is maximum.

Interannual and longer time-scale Atlantic hurricane activity has been linked to a variety of features includ- 
ing the El Niño/La Niña, Caribbean sea level pressure and tropospheric vertical wind shear, the stratospheric quasi-biennial oscillation, African West Sahel rainfall, and Atlantic SST (e.g., Gray 1984; Landsea et al. 1999). Because tropical cyclones extract energy from the warm tropical oceans and release the heat in the uppertropospheric outflow to fuel the storm's development, warmer SSTs can lead to more intense hurricanes. A few studies (Raper 1992; Shapiro and Goldenberg 1998; Saunders and Harris 1997; Molinari and Mestas-Nuñez 2003) have linked both concurrent and preceding SST anomalies in the Atlantic to local tropical cyclone activity. Enfield and Mestas-Nuñez (1999) and MestasNuñez and Enfield (1999) show that TNA SST variability is tied to simultaneous alterations in the high latitudes of the North Atlantic in a mode that operates primarily at the multidecadal time scale $(50-80 \mathrm{yr})$. Gray (1990), Gray et al. (1997), and Landsea et al. (1999) link these long-term SST variations to Atlantic tropical cyclone activity, primarily with the major hurricanes-those with maximum sustained surface winds of at least $50 \mathrm{~m} \mathrm{~s}^{-1}$. Goldenberg et al. (2001) conclude that, beginning in 1995, the North Atlantic switched back to the warm phase after two and a half decades in the cool phase. Along with the switch in SSTs, the Atlantic region has seen a resurgence of major hurricane activity. It is expected that variations in the size and intensity of the AWP might also be related to Atlantic hurricane activity; however, that relationship has not been documented in the literature yet. This paper thus will also explore the relationship between the AWP and Atlantic hurricanes.

The paper is organized as follows. Section 2 discusses the datasets and methods that are used in this paper. Section 3 describes and discusses variability of warm pools. Section 4 shows influences of the eastern Pacific warm pool and the AWP on the WH rainfall variability. Section 5 documents the relationship between the AWP and Atlantic hurricanes. Finally, section 6 provides a summary and discussion.

\section{Data and methods}

Many datasets are used in this study. The first is an improved extended reconstructed SST dataset on a $2^{\circ}$ latitude by $2^{\circ}$ longitude grid beginning January 1854 (Smith and Reynolds 2004), but here we only analyze monthly SST from January 1950 to December 2003. The second dataset is the National Centers for Environmental Prediction-National Center for Atmospheric Research (NCEP-NCAR) reanalysis from January 1950 to December 2003 on a $2.5^{\circ}$ latitude by $2.5^{\circ}$ longitude grid (Kalnay et al. 1996). Horizontal wind velocity is divided into a divergent part (the gradient of velocity potential) and a nondivergent part. In the Tropics, atmospheric heating associated with convection induces atmospheric convergence and divergence that drive atmospheric vertical motion and circulation. This direct circulation, comprised of zonal (Walker) and meridional (Hadley) circulations, is therefore best characterized by the divergent component of flow. We will focus on the distributions of atmospheric vertical motion and the divergent component of the wind when we discuss the regional Hadley circulation (e.g., Wang 2002, 2005).

Two monthly precipitation products are used: the Global Precipitation Climatology Project (GPCP) (Adler et al. 2003) and the Climate Prediction Center Merged Analysis of Precipitation (CMAP) (Xie and Arkin 1997). Both datasets blend satellite estimates and rain gauge data on a $2.5^{\circ}$ latitude by $2.5^{\circ}$ longitude grid available from January 1979 to present. We analyze both datasets, and our analyses show that precipitation patterns are very similar for both products. Recently, Yin et al. (2004) compare both products and find that they are in very good agreement in precipitation patterns and temporal variations. However, there are some differences between them in the tropical oceans and high-latitude land areas - a consequence of the input data. They conclude that for oceanic precipitation the GPCP is better than the CMAP. In this paper, we show the results of the GPCP from January 1979 to December 2003.

Another dataset is the hurricane data from the official U.S. National Hurricane Center archives (Jarvinen et al. 1984) for the North Atlantic basin, comprised of the North Atlantic Ocean, Gulf of Mexico, and Caribbean Sea. Hurricanes are defined as having maximum sustained 1-min surface winds of at least $33 \mathrm{~m} \mathrm{~s}^{-1}$. The database extends back to 1851 (Landsea et al. 2004), but only data from 1950 through 2003 are utilized here. The second half of the twentieth century is considered to be complete and reliable for the frequency and intensity of tropical cyclones in the database (Neumann et al. 1999), though short-lived, weak systems may have been missed before the era of geostationary satellite coverage began in the mid-1960s. This may cause a slight underreporting bias (estimated to be less than one hurricane every two years) in the period from 1950 to 1965.

Our analyses include the calculation of indices, composite averages, cross-correlations, and linear regressions. To isolate influences of different phenomena, we perform the partial correlation analyses (Wonnacott and Wonnacott 1986). Considering three variables $X$, $Y$, and $Z$, the partial correlation $R_{Y X / Z}$ is calculated as 
the correlation of $Y$ and $X$ after the influence of $Z$ has been removed from each of $Y$ and $X$ :

$$
R_{Y X / Z}=\frac{R_{Y X}-R_{Y Z} R_{X Z}}{\sqrt{1-R_{Y Z}^{2}} \sqrt{1-R_{X Z}^{2}}},
$$

where $R_{Y X}, R_{Y Z}$, and $R_{X Z}$ are correlation coefficients. In this paper, we also use contingency table analysis to examine the relationship between the AWP and hurricane frequency. In correlation calculations, the significance of the correlations is determined by the method of Sciremammano (1979).

\section{Variability of warm pools}

The Western Hemisphere warm pool (WHWP), the region covered by water warmer than $28.5^{\circ} \mathrm{C}$, undergoes large annual and interannual variations (Wang and Enfield 2001, 2003). Near this SST threshold widescale deep tropospheric convection readily occurs. Not only is the choice of $28.5^{\circ} \mathrm{C}$ based on limiting the WHWP to a closed region, it is also based on the fact that the depth of the $28.5^{\circ} \mathrm{C}$ isotherm is closest to the average mixed layer depth in the WHWP. Unlike the Indo-Pacific warm pool (e.g., Webster and Lukas 1992), which straddles the equator, the WHWP lies entirely north of the equator. Sandwiched between North and South America and between the tropical North Pacific and Atlantic Oceans, the WHWP is the second largest body of very warm water on earth and hosts the second largest diabatic heating center of the Tropics during the boreal summer (Wang and Enfield 2003). At various stages of development, the WHWP comprises the eastern North Pacific west of Central America, the intra-Americas sea (IAS) (i.e., the Gulf of Mexico and the Caribbean) and the western TNA. Figure 2a shows the June-August (JJA) WHWP area anomaly index of Wang and Enfield (2003), which is calculated as the anomalies of the area of SST warmer than $28.5^{\circ} \mathrm{C}$ divided by the climatological JJA WHWP area. From 1950 to 2003, the five largest WHWPs $(1958,1969,1983$, 1987, and 1998) have occurred during the boreal summers following Pacific El Niño events (Fig. 2b). However, four other El Niño events (1966, 1973, 1977, and 1992) are not associated with large WHWPs.

The Central America landmass divides the WHWP into two ocean regions: 1) the eastern North Pacific warm pool and 2) the Atlantic warm pool. As shown in Wang and Enfield $(2001,2003)$, the eastern North Pacific warm pool and AWP peak around May and September, respectively. Figure 2c shows the component area index for the eastern North Pacific warm pool, which is calculated as the anomalies of the area of SST warmer than $28.5^{\circ} \mathrm{C}$ divided by the climatological April to June (AMJ) eastern North Pacific warm pool area. In all of the five largest WHWPs following El Niño peaks, the eastern North Pacific warm pools are large. The calculation shows that the correlation of the AMJ eastern North Pacific warm pool index and the AMJ Niño-3 SST anomalies reaches the high value of 0.87 . This is an expected result since the eastern North Pacific warm pool is close to the ENSO region of maximum variance and is directly related to ENSO variability.

Because we focus on non-ENSO factors that influence WH rainfall and Atlantic hurricanes, we will mainly consider the AWP. We note two facts: 1) the annual precipitation for Central America and the Caribbean Sea exhibits a bimodal distribution with maxima during June and September-October (e.g., Magaña et al. 1999; Taylor et al. 2002), and 2) the AWP peaks around September and disappears in the boreal winter (Wang and Enfield 2001, 2003). Therefore, our analysis of rainfall will address variability during both May-July (MJJ) and August-October (ASO). Figures 3a and 3b show the MJJ and ASO percentage area anomalies of the AWP, calculated as the area anomalies of SST warmer than $28.5^{\circ} \mathrm{C}$ normalized by the MJJ and ASO climatological AWP area, respectively. In four (1958, 1969, 1987, and 1998) of the five largest WHWPs (Fig. 2a), the AWP in MJJ and ASO is also large. For 1983 (one of the five largest WHWPs), the AWP is normal in both MJJ and ASO. This was a year in which the effects of El Niño in the eastern Pacific lingered late into the decay phase (Rasmusson and Wallace 1983), affecting primarily the eastern North Pacific warm pool, as shown in Fig. 2c. Figure 3a shows that for the years of 1958, 1969, and 1998 (an El Niño event occured in the preceding winter), the AWP in MJJ is much larger than for other years. Our calculations show that the correlation between the DJF Niño-3 SST anomalies and the MJJ AWP index is 0.60 (above the 95\% level). However, the contemporaneous correlation of the MJJ Niño-3 SST anomalies and the MJJ AWP index is not significant.

How are the AWPs in ASO related to ENSO? To answer this question, we first define large and small warm pools. We identify a warm pool $25 \%$ larger (smaller) than the climatological area as a large (small) warm pool; otherwise, warm pools are classified as normal or neutral. From 1950 to 2003, there are 14 large warm pools $(1952,1958,1969,1980,1987,1990,1995$, 1997, 1998, 1999, 2000, 2001, 2002, and 2003) and 15 small warm pools $(1950,1965,1967,1971,1972,1974$, 1975, 1976, 1977, 1982, 1984, 1985, 1986, 1992, and 1994). Based on well-documented ENSO events, no Pa- 

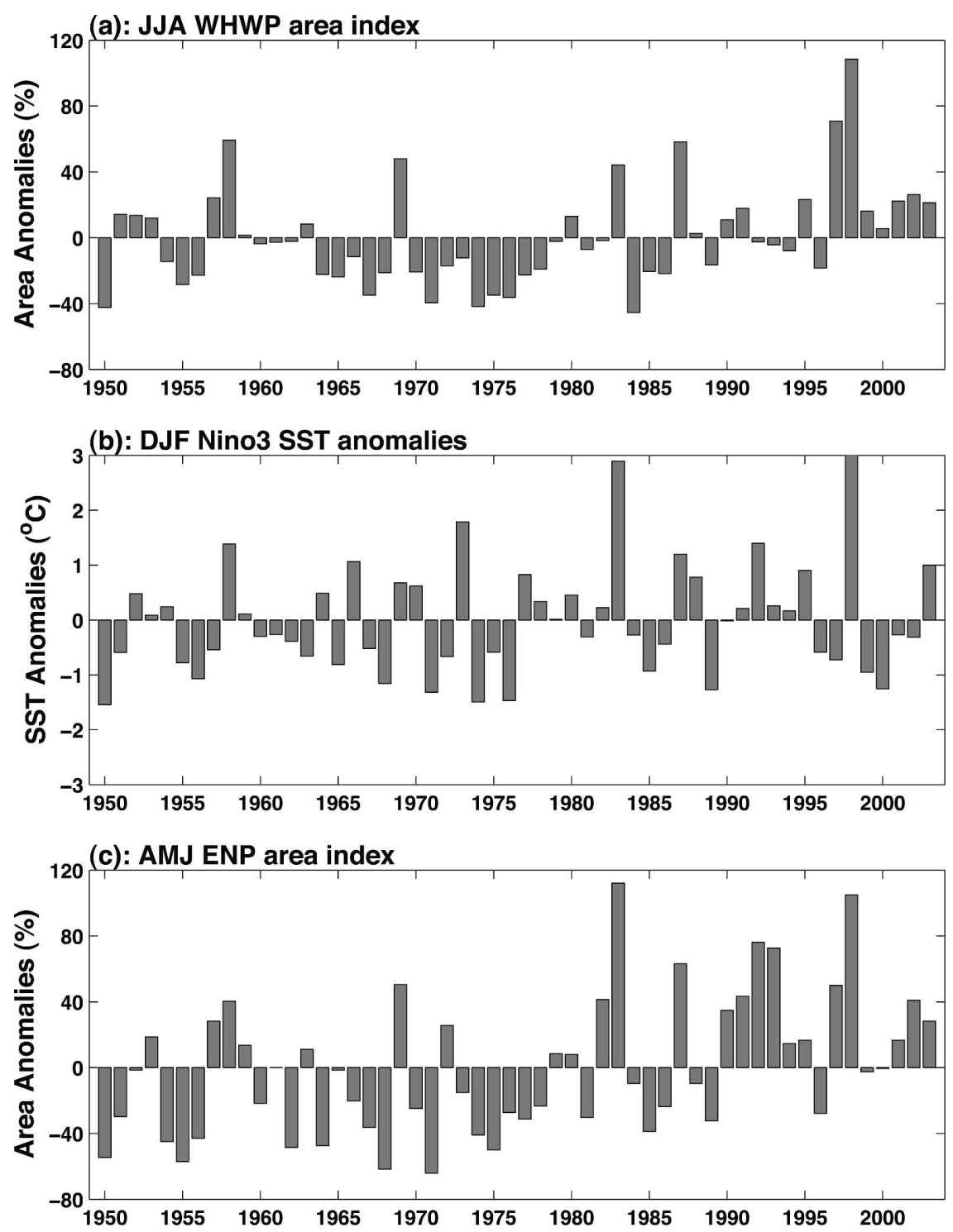

FIG. 2. (a) JJA Western Hemisphere warm pool (WHWP) area anomaly index (\%), (b) DJF Niño-3 SST anomalies, and (c) AMJ eastern North Pacific (ENP) warm pool area anomaly index (\%). The warm pool indices are calculated as the anomalies of the area of SST warmer than $28.5^{\circ} \mathrm{C}$ divided by the climatological (JJA and AMJ, respectively) warm pool area.

cific El Niño occurs in the preceding boreal winter for 9 of the 14 years of large warm pools $(1952,1980,1990$, 1995, 1997, 1999, 2000, 2001, and 2002). Among the 15 small warm pools, there are 10 cases $(1950,1967,1972$, $1975,1977,1982,1984,1985,1992$, and 1994) in which the preceding winter does not show a La Niña condition in the Pacific. Thus, about two-thirds of the overall warm pool variability in ASO (both large and small warm pools) appears to be unrelated to ENSO. The calculations show that the correlation between the DJF Niño-3 SST anomalies and the ASO AWP index is marginally significant. However, the contemporaneous cor- relation of the ASO Niño-3 SST anomalies and the ASO AWP index is not significant. This reflects the fact that 1) large AWPs have no clear relation to contemporaneous El Niño development and 2) by ASO of the following year the Pacific El Niño anomaly has almost always disappeared.

Based on our definition of the AWP (SST $\geq$ $28.5^{\circ} \mathrm{C}$ ), for most of the time the AWP is geographically different from the tropical North Atlantic (TNA). However, there is some overlap between the AWP and TNA domains, but only when the eastern limits of the large warm pool extend east of the $60^{\circ} \mathrm{W}$ meridian. In 
(a): MJJ Atlantic warm pool area index

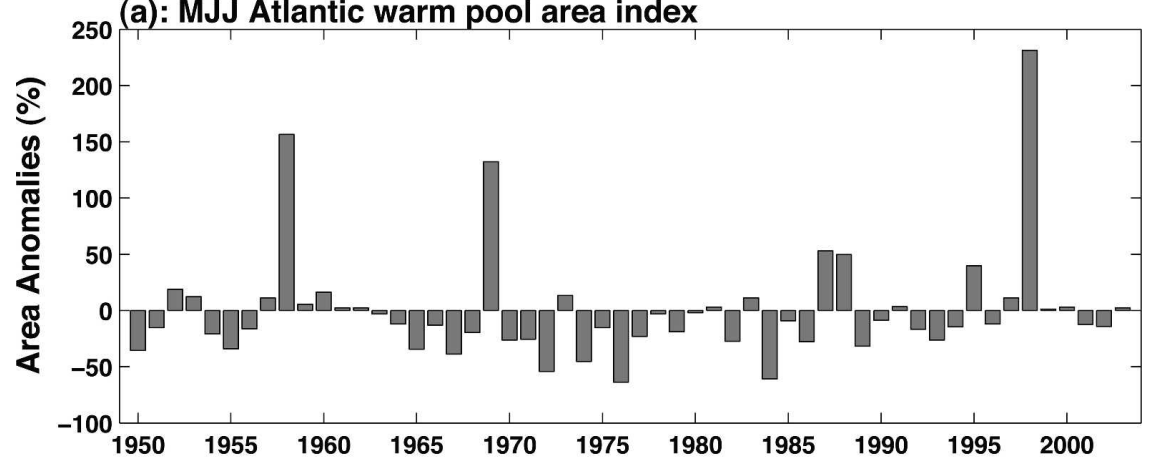

(b): ASO Atlantic warm pool area index

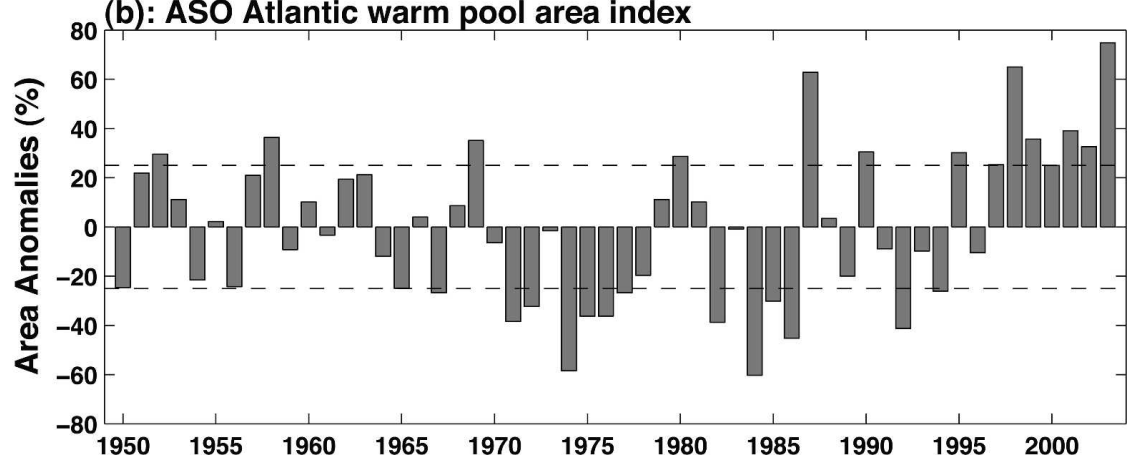

FIG. 3. (a) MJJ Atlantic warm pool area anomaly index (\%) and (b) ASO AWP area anomaly index $(\%)$. The indices are calculated as the anomalies of the area of SST warmer than $28.5^{\circ} \mathrm{C}$ divided by the climatological (MJJ and ASO, respectively) AWP area. The climatological AWP areas in MJJ and ASO are $1.5 \times 10^{6} \mathrm{~km}^{2}$ and $5.9 \times 10^{6} \mathrm{~km}^{2}$, respectively. Two straight dashed lines in (b) represent the warm pool $25 \%$ larger and smaller than the ASO climatological warm pool area.

spite of this, the AWP is related to the variations in the TNA. The contemporaneous correlations between the AWP area index and the TNA SST anomalies in MJJ and ASO are 0.57 and 0.76 , respectively. The lower correlation in MJJ reflects that the AWP is more disconnected from the TNA in MJJ than in ASO. The AWP area index in Fig. $3 \mathrm{~b}$ also shows the signal of the Atlantic multidecadal oscillation, which switched its phases around 1965 and 1995 (e.g., Kerr 2000; Enfield et al. 2001). Note that removal of the linear trend in Fig. $3 \mathrm{~b}$ for the data record period from 1950 to 2003 does not change rainfall correlation patterns shown later. Thus, we use the nondetrended AWP area index of Fig. $3 \mathrm{~b}$ in the following calculations.

In Fig. 4, we composite the 14 large warm pools and the 15 small warm pools, comparing them with the ASO climatological mean warm pool. The large warm pools are almost three times larger than the small ones (their average areas are $8.0 \times 10^{6} \mathrm{~km}^{2}$ and $2.8 \times 10^{6}$ $\mathrm{km}^{2}$, respectively). In summary, the variability of the AWP is large, and although ENSO teleconnections are clearly influential on the Atlantic Ocean, the size of the AWP during ASO does not necessarily follow the
ENSO events, but it is more related to the TNA SST anomalies.

\section{Rainfall variability}

Before we focus on the influence of the Atlantic Ocean on rainfall variability in the $\mathrm{WH}$, we first examine the impact of the eastern North Pacific warm pool on rainfall.

\section{a. Eastern North Pacific warm pool}

As shown in Wang and Enfield $(2001,2003)$, the eastern North Pacific warm pool starts to develop in the early boreal spring and matures around May. We are thus interested in seeing its associated rainfall patterns from April to June. Figure 5a shows the correlation map of the AMJ rainfall anomalies with the AMJ eastern North Pacific warm pool area index. Positive correlation is found over the equatorial eastern Pacific and the tropical and subtropical North Atlantic, whereas negative correlation is located in the region of the eastern Pacific ITCZ and from the equatorial eastern South 
(a): Large warm pools

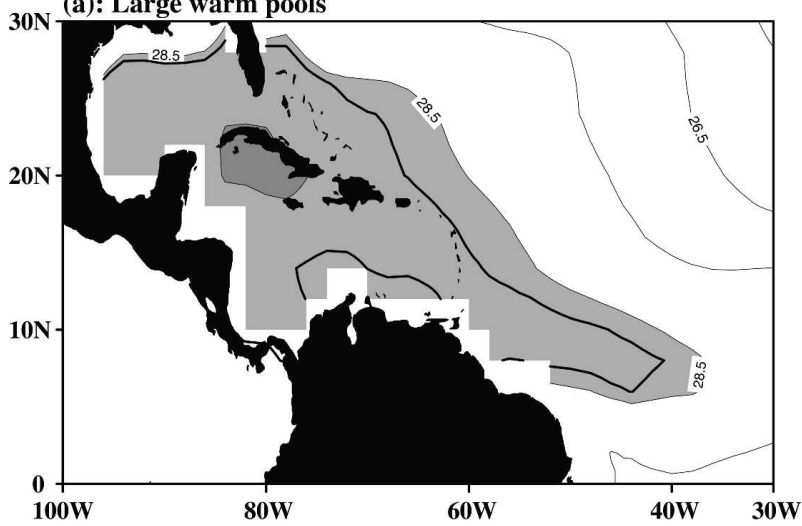

(b): Small warm pools

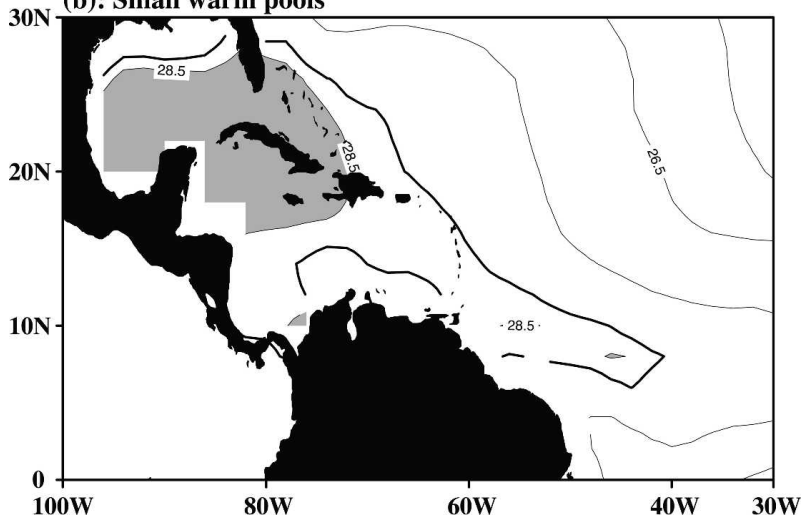

FIG. 4. SST composites of (a) large Atlantic warm pools and (b) small Atlantic warm pools during ASO. The dark contour represents ASO climatological SST warmer than $28.5^{\circ} \mathrm{C}$.

America to the tropical South Atlantic. This correlation pattern is very similar to that of the AMJ rainfall anomalies with the AMJ Niño-3 SST anomalies, as shown in Fig. 5b. This is not a surprising result since the eastern North Pacific frequently has significant SST anomalies that persist well into the following spring of an El Niño event. In other words, interannual variation of the eastern North Pacific warm pool is directly related to El Niño events (as showed in the last section, their correlation is 0.87 ). The linear regression maps of the AMJ rainfall anomalies on the AMJ eastern North Pacific warm pool index and on the AMJ Niño-3 SST anomalies also display similar pattern and amplitude (not shown).

However, Fig. 5 does not necessarily mean that El Niño in the Pacific is directly responsible for the rainfall correlations in the Atlantic sector. In the boreal spring, the TNA is being warmed through atmospheric processes connected to El Niño. The TNA SST anomalies are correlated with the meridional displacement of the Atlantic ITCZ. Therefore, the Atlantic rainfall correlations can be explained as being associated with El
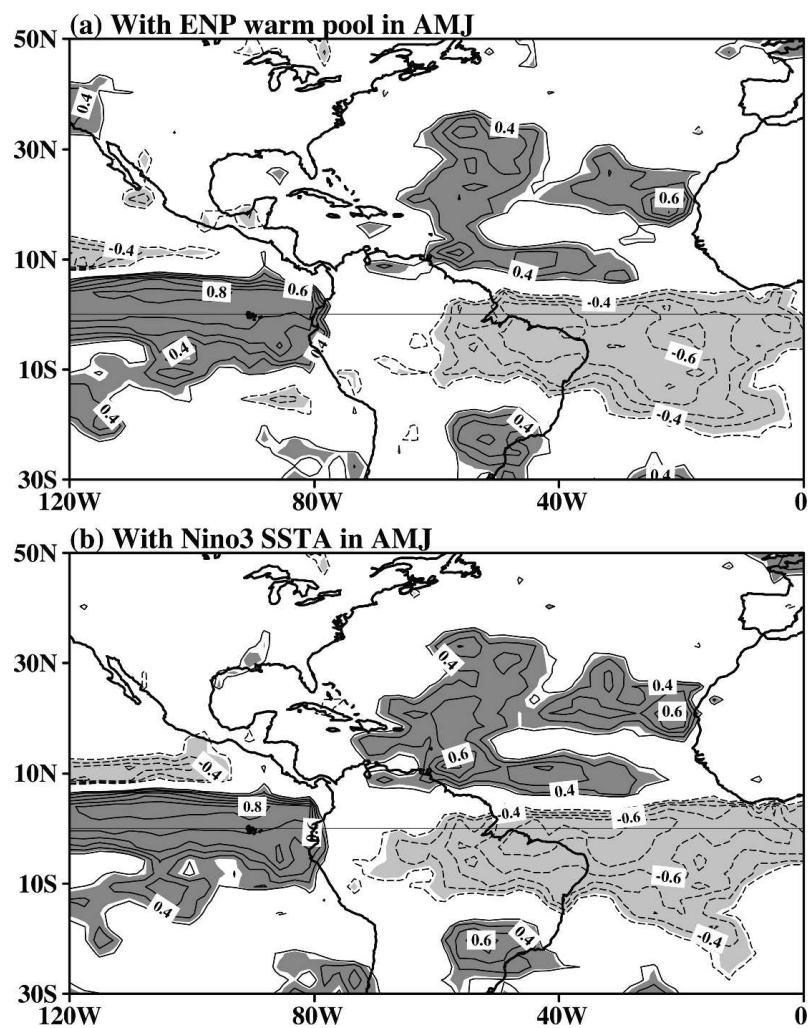

FIG. 5. (a) Correlation of AMJ rainfall anomalies with the AMJ eastern North Pacific warm pool index, and (b) correlation of AMJ rainfall anomalies with the AMJ Niño-3 SST anomalies. The contour interval is 0.1 and the correlations below \pm 0.3 are not plotted. The $90 \%$ and $95 \%$ significant levels are 0.33 and 0.39 , respectively. The shadings represent correlation larger than 0.33 (dark for positive and light dark for negative).

Niño by proxy through the TNA SST and the Atlantic ITCZ (e.g., Enfield 1996; Taylor et al. 2002). This is also evidenced by the similar rainfall correlation pattern between Fig. 1c and Fig. 5. El Niño also can affect rainfall over the remote region of the tropical Atlantic via the El Niño-related tropospheric warming and stabilization of the entire tropical troposphere (e.g., Chiang et al. 2002; Chiang and Sobel 2002; Neelin et al. 2003).

\section{b. Atlantic warm pool}

As stated in section 3, our analyses will focus on the influence of the AWP on rainfall during MJJ and ASO. We first examine the relationship between rainfall and the AWP in MJJ. The contemporaneous correlation of the MJJ rainfall anomalies with the MJJ AWP area index is shown in Fig. 6a. Some small regions of rainfall correlation reflect the smallness of the AWP in MJJ when the AWP is disconnected from the TNA. The ENSO-influenced rainfall during MJJ is displayed in Fig. 6b. The Atlantic pattern in Fig. 6b is similar to that 

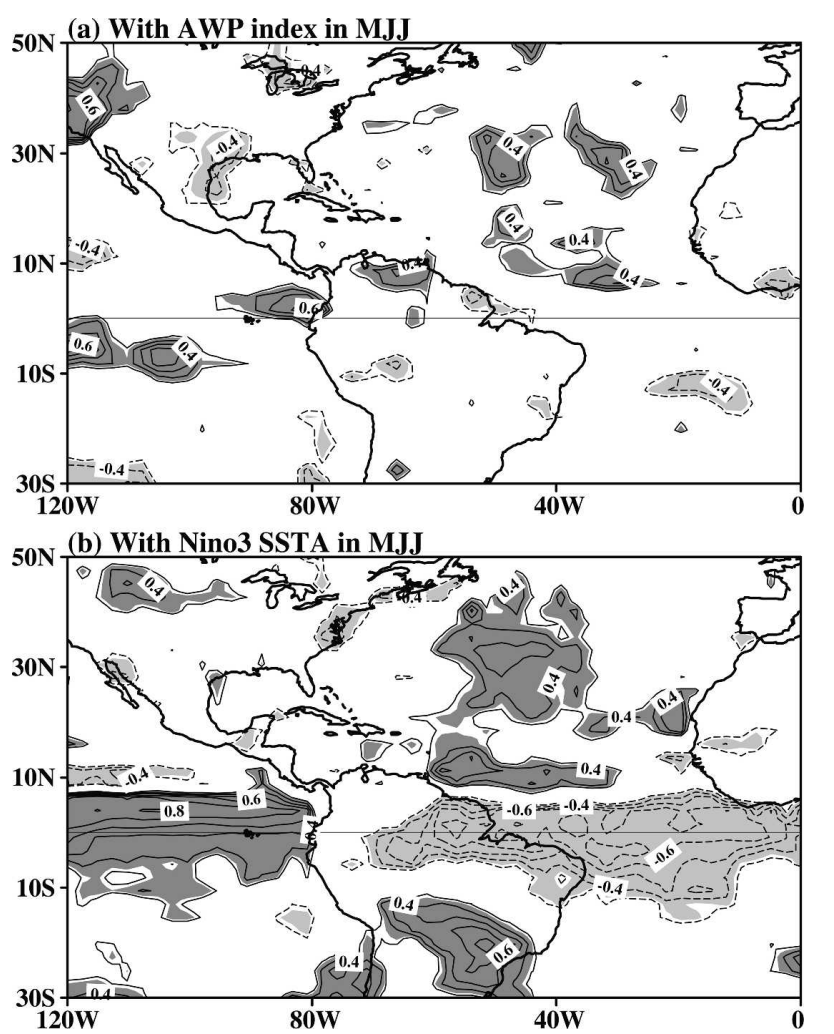

FIG. 6. (a) Correlation of MJJ rainfall anomalies with the MJJ AWP index, and (b) correlation of MJJ rainfall anomalies with the MJJ Niño-3 SST anomalies. The contour interval is 0.1 and the correlations below \pm 0.3 are not plotted. The $90 \%$ and $95 \%$ significant levels are 0.33 and 0.39 , respectively. The shadings represent correlations larger than 0.33 (dark for positive and light dark for negative).

of Fig. 1c, suggesting again that ENSO affects Atlantic rainfall by proxy through the TNA SST and the Atlantic ITCZ.

The correlation map of the ASO rainfall anomalies with the ASO AWP area index is shown in Fig. 7a. Significant positive correlation is found over the Caribbean, Mexico and Central America, and the southeast Pacific, while negative correlation is located over the northwest U.S. and Great Plains regions and eastern South America. We also composite the ASO rainfall anomalies for the large and small warm pools (not shown), and the rainfall patterns are similar to Fig. 7a. As discussed in section 3, the size of the AWP is correlated with the TNA SST anomalies. Figure 7b shows the correlation between the ASO rainfall anomalies and the ASO TNA SST anomalies. As expected, the correlation patterns in Figs. 7a and $7 \mathrm{~b}$ are similar. However, the positive correlation area over the Caribbean and southeastern Mexico region in Fig. 7a is larger than in Fig. 7b, while the positive correlation off west Africa in Fig. $7 b$ extends westward and covers a larger area.
The negative correlation area over eastern South America in Fig. 7a is much larger than in Fig. 7b.

To remove the influences of the TNA and ENSO, we perform the partial correlation analyses. Figure $7 \mathrm{c}$ shows the partial correlation of the ASO rainfall anomalies and the ASO AWP area index after removing the influence of the TNA SST anomalies. Comparison of Fig. 7c with Fig. 7a shows that rainfall over the northern Caribbean, southern Mexico, and eastern South America is mainly related to the size of the AWP. Rainfall over northwest U.S. and Great Plains regions seems to relate to both the TNA SST anomalies and the AWP size (as the TNA warms up, the AWP becomes larger). In other words, the impacts of the AWP and the TNA SST anomalies on rainfall over the northwest United States and Great Plains cannot be separated. The AWP is important because it is a moisture source for rainfall in North America (Bosilovich and Schubert 2001,2002) and is closer to the northwest United States/Great Plains than the TNA. Figures $7 a-c$ also suggest that the positive rainfall correlation in the northern TNA region is due to the local SST anomalies since the positive correlation disappears after removing the TNA SST anomalies.

Figure 7d shows the partial correlation of the ASO rainfall anomalies and the ASO AWP area index after removing the Niño-3 SST anomalies. The correlation map in Fig. $7 d$ is very similar to that in Fig. 7a. The similar correlation suggests that ENSO has little or nothing to do with the correlation patterns in Fig. 7a. This is consistent with the result presented in section 3 in that the AWP is not significantly correlated with the Niño-3 SST anomalies during ASO. The result is also supported by Fig. 1b and by other studies (e.g., Giannini et al. 2000; Diaz et al. 2001; Chen and Taylor 2002), which show that the ENSO-related rainfall correlation during the boreal summer is negative over the Caribbean, the Pacific side of Central America, and the southeast Pacific. The ENSO-related rainfall correlation is insignificant or positive over the northwest United States (Fig. 1b). That is, the signs of rainfall correlation with the AWP in these regions are opposite to those for Niño-3 SST anomalies.

A large (small) warm pool having more (less) rainfall in the core region of the warm pool is consistent with oceanic and atmospheric conditions observed in the warm pool. Wang and Enfield $(2001,2003)$ show that the warm SST anomalies in the AWP region are associated with a decrease in sea level pressure anomalies and an anomalous increase in atmospheric convection and cloudiness. Years with a large warm pool have lower sea level pressure and tropospheric vertical wind shear, greater moist instability over the region of the 

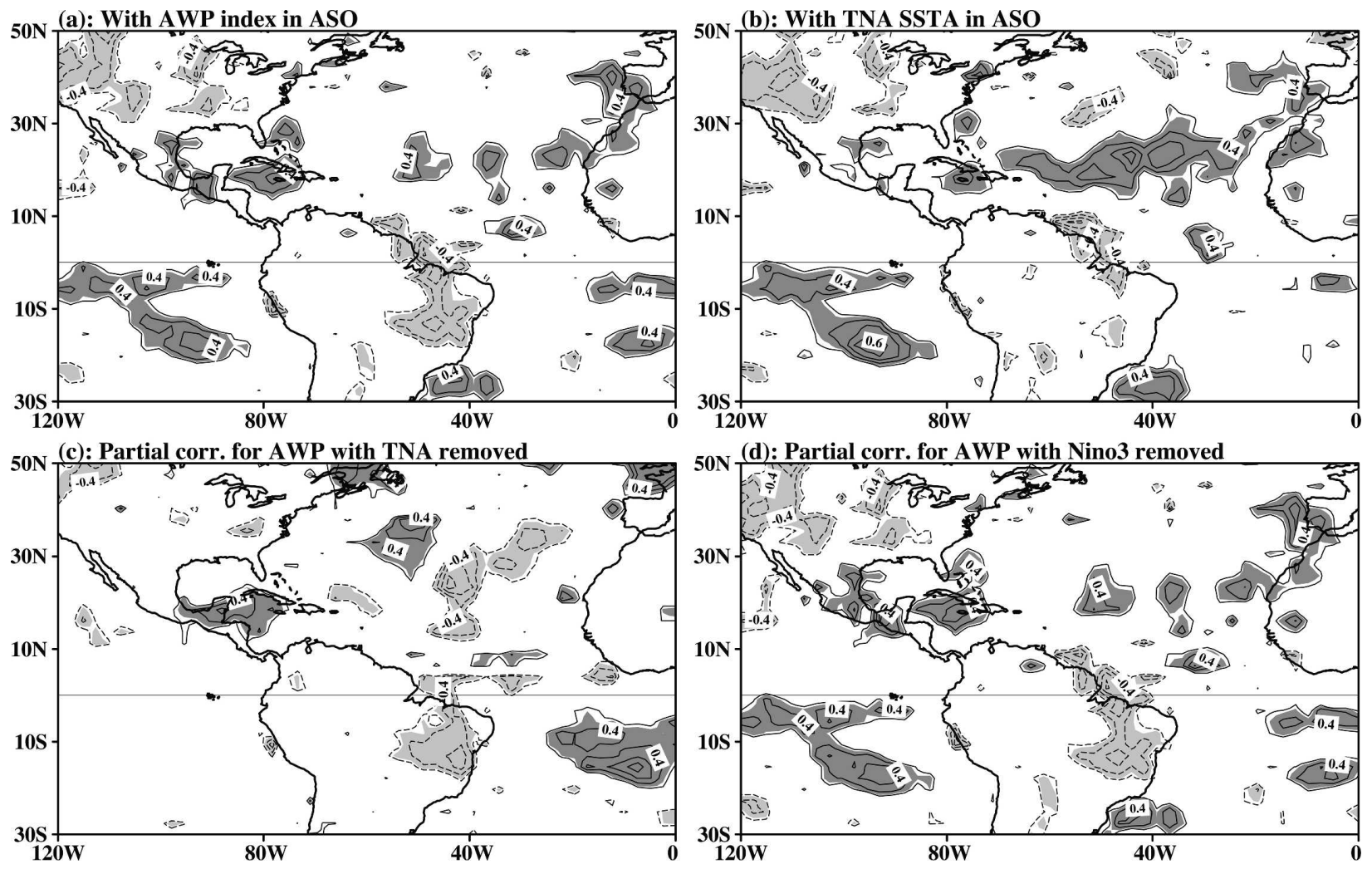

FIG. 7. (a) Correlation of ASO rainfall anomalies with the ASO AWP index, (b) correlation of ASO rainfall anomalies with the ASO SST anomalies in the TNA $\left(6^{\circ}-22^{\circ} \mathrm{N}, 60^{\circ}-15^{\circ} \mathrm{W}\right)$, (c) partial correlation of ASO rainfall anomalies and the ASO AWP index with TNA SST anomaly influence removed, and (d) partial correlation of ASO rainfall anomalies and the ASO AWP index with Niño-3 SST anomaly influence removed. The contour interval is 0.1 and the correlations below \pm 0.3 are not plotted. The $90 \%$ and $95 \%$ significant levels are 0.33 and 0.39 , respectively. The shadings represent correlation larger than 0.33 (dark for positive and light dark for negative).

AWP, and a weakened tropical upper-tropospheric trough (Knaff 1997). These conditions lead to generally greater contemporaneous summer rainfall over the region surrounding the warm pool and an increase in tropical cyclone activity (see section 5).

The negative correlation over the Great Plains region in Fig. 7a can be explained from a moisture transport perspective. The Gulf of Mexico and Caribbean Sea serve as a source of water vapor for rainfall in North, Central, and South America (e.g., Mo and Higgins 1996; Hu and Feng 2001). We can discuss the relationship between the Great Plains rainfall and AWP from two points of view: First, much of the summer moisture that precipitates over the Great Plains is exported from the warm pool to the north (Bosilovich and Schubert 2001, 2002). If more (less) moisture precipitates over the warm pool, it seems plausible that less (more) would be available for transport into the Great Plains region. Second, water vapor for rainfall over the Great Plains is transported by the atmospheric wind. Figures $8 \mathrm{a}$ and $8 \mathrm{~b}$ show the ASO climatological $925-\mathrm{mb}$ wind and the correlation between the ASO AWP index and the ASO 925-mb wind anomalies, respectively. During ASO, surface wind normally blows from the AWP into the Great Plains region (Fig. 8a), consistent with the role of moisture transport for rainfall of the Great Plains. However, the AWP-correlated wind anomalies in the region of the Great Plains and AWP are southward (Fig. 8b). That is, a large (small) AWP is associated with southward (northward) wind anomalies and thus disfavors (favors) moisture transport to the Great Plains for rainfall.

\section{c. Drizzle under stratus cloud over the southeast Pacific}

Associated with cold SST, the southeast Pacific is a region of anticyclone flow with climatological subsidence. In the subsidence region of the southeast Pacific, the surface winds evaporate water vapor from the ocean, but the atmospheric inversion prevents the moist air from rising to significant elevations. A thin layer of stratus or stratocumulus clouds form at the base of the inversion. A light precipitation (drizzle) under the stratus cloud deck thus appears over the south- 
(a): Climatological wind in ASO

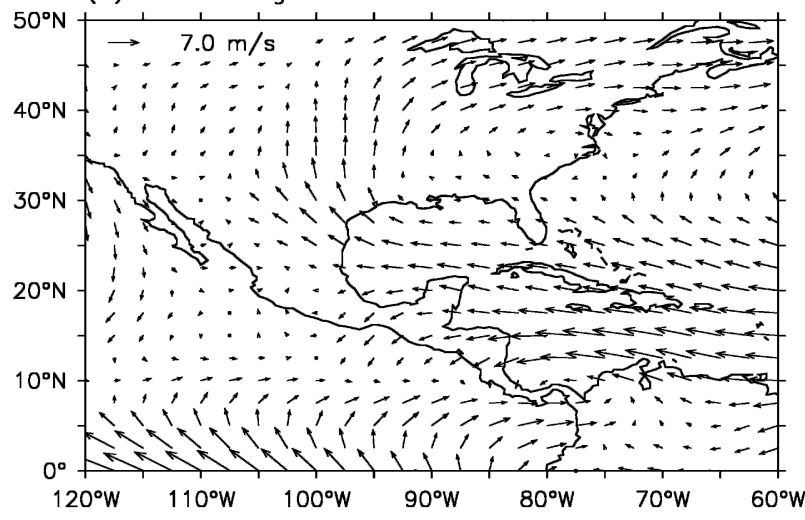

(b): Corr. of ASO AWP index and wind anomalies

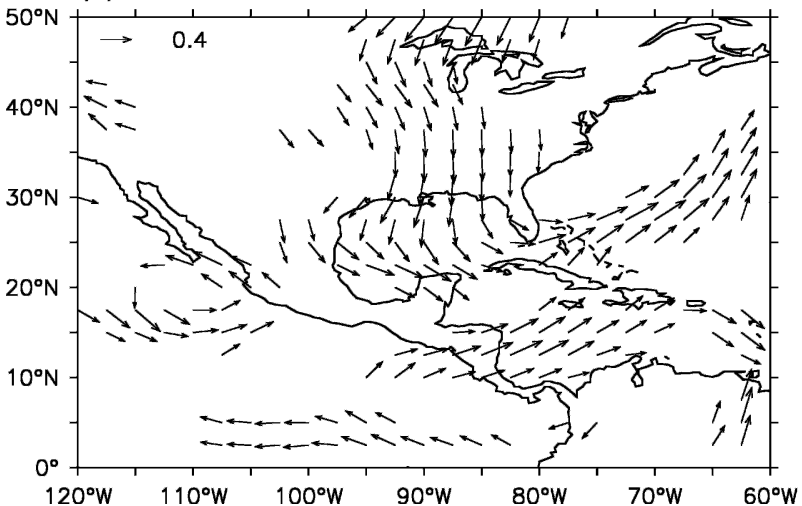

FIG. 8. (a) Climatological wind at $925 \mathrm{mb}$ during ASO, and (b) correlation of the ASO AWP index with the ASO 925-mb wind anomalies. In (b) only winds above the $95 \%$ significance level are plotted.

east Pacific (e.g., Wang et al. 2004). The drizzle is an indicator of what is happening aloft with the subsidence. Despite the light precipitation associated with the stratus cloud, the southeast Pacific is an important region that contributes to climate asymmetry in the eastern Pacific (Philander et al. 1996). Figure 7a shows that rainfall anomalies over the southeast Pacific are positively correlated with the AWP area index.

What is the mechanism for the positive rainfall correlation in the southeast Pacific shown in Fig. 7a? It is unlikely that this feature is related to ENSO because Fig. 7d still shows a positive correlation over the southeast Pacific after the ENSO effect has been removed from the calculation. Figure 1b does not support ENSO either since it shows either insignificant or negative correlation with ENSO in this region. Another possibility is the local SST anomalies in the southeast Pacific that may contribute to the positive correlation in the southeast Pacific. The map of partial correlation for AWP and rainfall with the southeast Pacific SST anomalies removed is virtually identical to Fig. 7a (not shown).
Therefore, the local SST anomalies cannot explain the positive correlation in the southeast Pacific in Fig. 7a.

The remaining candidates are the TNA and AWP. In fact, the positive correlation over the southeast Pacific disappears after the TNA SST anomalies (related to the AWP) are removed (Fig. 7c). The question is: how do the TNA and AWP link to the southeast Pacific? The possible linkage may be the regional Atlantic Hadley circulation (Wang 2002, 2005). Figure 9 shows composites of the 200-mb velocity potential and divergent wind anomalies for the large and small warm pools, calculating by the NCEP-NCAR reanalysis from 1950 to 2003. Large warm pools are associated with a strong regional Hadley circulation emanating from the WHWP into the southeast Pacific where anomalous convergence is located (Fig. 9a). The converse occurs for small warm pools (Fig. 9b). Therefore, large (small) warm pools and warm (cold) TNA strengthen (weaken) subsidence over the southeast Pacific. A dynamical consistency between the divergence and vertical motion fields is checked by compositing the $500-\mathrm{mb}$ vertical velocity anomalies over the southeast Pacific for the large warm pools and small warm pools, as shown in Fig. 10. Figure 10 confirms that large (small) warm pools are associated with anomalous descending (ascending) motion over the southeast Pacific.

\section{Atlantic hurricanes}

The rainfall correlation maps in Fig. 7 show that the AWP and TNA have a positive correlation off West Africa extending westward and covering the tropical eastern north Atlantic. This is the region where easterly waves moving offshore from the Sahel region frequently become hurricanes during August and September, which then propagate westward toward the Caribbean and North America. Increased rainfall is indicative of more atmospheric convective activity, which favors cyclogenesis (Gray 1968). Knaff (1997) has shown that, when the Caribbean and western TNA are warm, the troposphere is less stable, rainfall in the region is greater, and hurricane activity increases. Our results support the notion that large warm pools are associated with greater Atlantic hurricane activity.

Figure 11a compares the total numbers of Atlantic hurricanes with the ASO AWP area anomaly index. Our calculation shows that the correlation coefficient of the AWP area with the Atlantic hurricanes is 0.33 , which is above the $95 \%$ significance level. This is comparable to the influences of ENSO and the TNA on hurricanes (the correlations of Atlantic hurricanes with the ASO Niño-3 and TNA SST anomalies are -0.39 and 0.32 , respectively). The hurricane partial correlation for the AWP with the Niño-3 SST anomalies removed is 

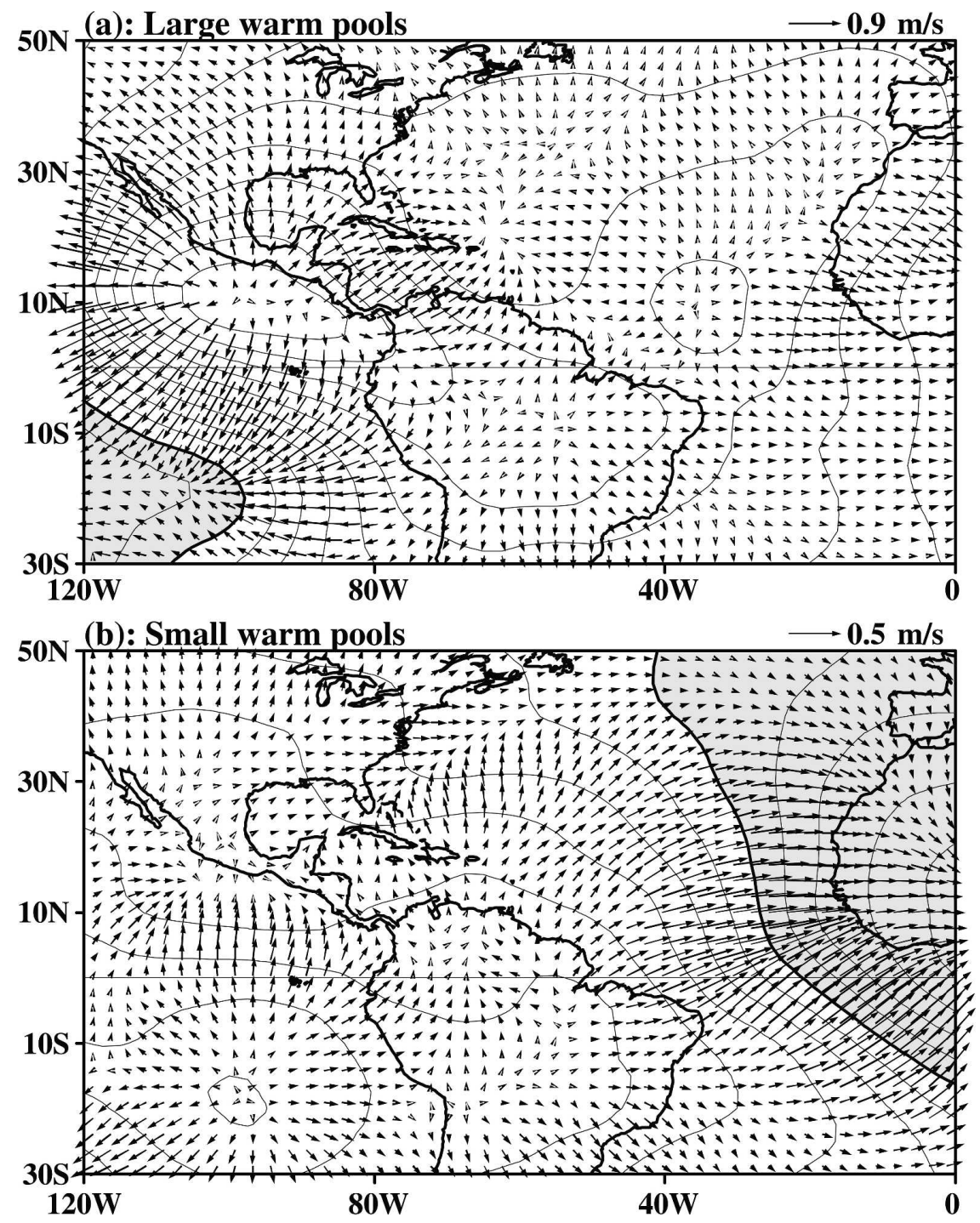

FIG. 9. Composites of the 200-mb velocity potential and divergent wind anomalies during ASO for (a) large and (b) small Atlantic warm pools.

0.43. However, if we remove either the TNA SST anomalies or the AWP index, hurricane correlation for the AWP index or for the TNA SST anomalies drops below the $95 \%$ significance level. Again, the impacts of the AWP and TNA cannot be separated. The correlations are also consistent with the results of section 3 in that the AWP is more independent of ENSO than the TNA. The AWP and TNA are related to hurricane activity because the SST partly determines the maximum potential development of the storms. Within the warm pool, the temperatures required for development extend to greater depth than elsewhere, thus reducing the tendency of a storm to diminish that potential by mixing cool subsurface water into the upper warm layer (Bender and Ginis 2000; Shay et al. 2000). Hence, the size of the warm pool is important because it affects the area (fetch) over which the intensity and heat content required for sustained development are available.

Gray $(1968,1979)$ show that a major inhibiting factor for tropical cyclone and hurricane development is tropospheric vertical wind shear. The vertical wind shear (VWS) between the upper troposphere $(200 \mathrm{mb})$ and the lower troposphere $(850 \mathrm{mb})$ can be calculated as

$$
\mathrm{VWS}=\sqrt{\left(U_{200}-U_{850}\right)^{2}+\left(V_{200}-V_{850}\right)^{2}} .
$$

The vertical wind shear in the IAS region during ASO is shown, in Figs. $11 \mathrm{~b}$ and 11c, in comparison with the AWP area index and the total numbers of the Atlantic hurricanes. The calculation shows that the VWS is sig- 


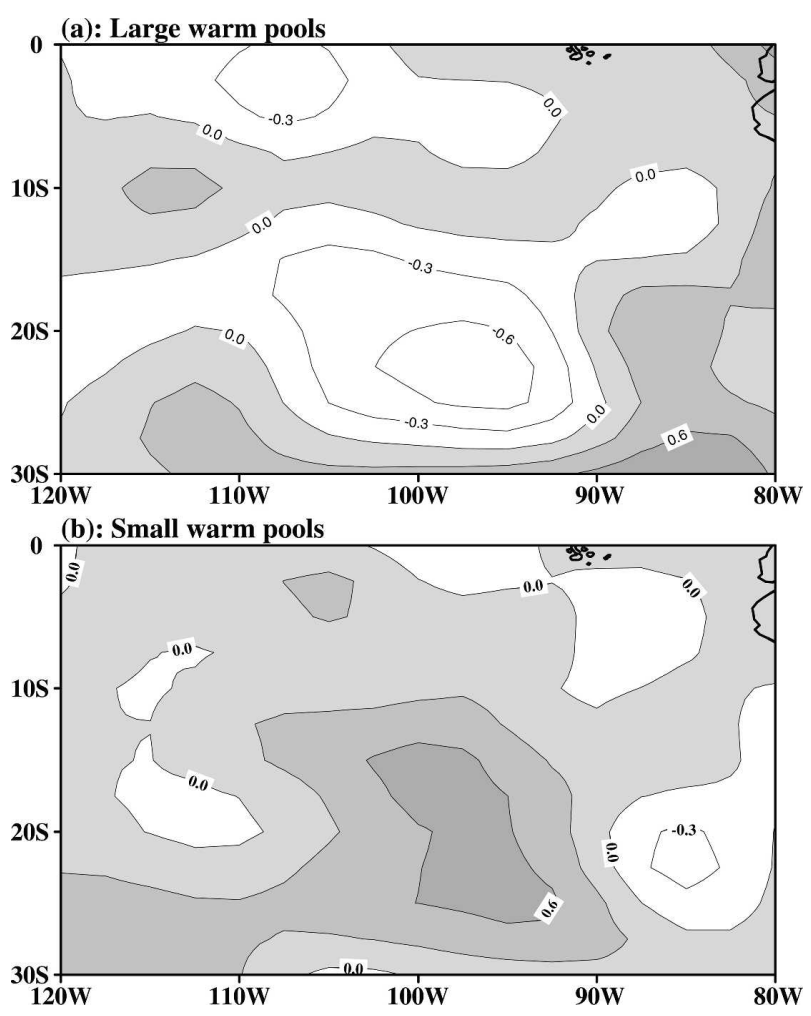

FIG. 10. Composites of the $500-\mathrm{mb}$ vertical velocity anomalies $\left(10^{-4} \mathrm{hPa} \mathrm{s}^{-1}\right)$ during ASO for (a) large and (b) small Atlantic warm pools. The vertical velocity is taken the negative of the pressure vertical velocity in the reanalysis, i.e., positive values indicate an upward movement of air parcels. Positive values are shaded.

nificantly correlated with the AWP area index $(-0.36)$ and the total numbers of Atlantic hurricanes $(-0.47)$. Wang and Enfield $(2001,2003)$ show that the IAS SST anomalies are correlated with the IAS sea level pressure and cloudiness anomalies. Combining these results, the physical mechanism that links the warm pool and Atlantic hurricane activity can be described as follows: Warm water causes a decrease in sea level pressure that results in an anomalous increase in deep convective activity (also see Knaff 1997) and atmospheric cloudiness. This is associated with a weak vertical wind shear (Figs. 11b and 11c) that can strengthen the tropical cyclone by helping the organization of deep convection and thus increases Atlantic hurricane activity. The weaker vertical wind shear means weaker upper-level $(200 \mathrm{mb})$ westerly flow and weaker low-level $(850 \mathrm{mb})$ easterly flow. The weakened low-level easterlies may feed back to the ocean by further warming SSTs through reduced latent and sensible heat flux loss.

The Atlantic hurricanes can be grouped into subsets based on the region of their formation, intensity, and season. We stratify them into seven groups: 1) forming in the IAS (including the Gulf of Mexico and the Caribbean Sea), 2) forming in the TNA $\left(0^{\circ}-30^{\circ} \mathrm{N}, 60^{\circ} \mathrm{W}-\right.$ $\left.0^{\circ}\right), 3$ ) all categories 1-2 (based on the Saffir-Simpson hurricane scale), 4) all categories 3-5 (major hurricanes), 5) forming in early season [June-July (JJ)], 6) forming in midseason [August-September (AS); also called Cape Verde], and 7) forming in late season [October-November (ON)]. The official Atlantic hurricane season is from 1 June to 30 November, and it is traditionally divided into JJ, AS, and ON. Table 1 compares the mean hurricane count per year for large warm pools with that for small warm pools for these seven hurricane groups and the total Atlantic hurricanes. Statistical significance of differences of the mean is assessed by applying a Student's $t$ test. Hurricanes forming in the TNA, major hurricanes, hurricanes forming in the mid- and late seasons, and all Atlantic hurricanes show significantly different means for large and small warm pools (Table 1). Among these significant groups, the two largest differences for small and large warm pools are those of major hurricanes and those forming in the TNA. As an example, Fig. 12 contrasts major hurricane tracks for both large warm and small warm pools. The number of major hurricanes (40) in 14 years of large warm pools is much larger than that (24) in 15 years of small warm pools. This may reflect that large (small) warm pools correspond to a deep (shallow) warm upper ocean and a weak (strong) tropospheric vertical wind shear, both favor (disfavor) hurricane development or intensification.

The linear correlations of hurricanes with the JJ, AS, and ON warm pool indices are calculated, as shown in Table 2. From this table, several points can be mentioned. First, the linear correlations of the AWP index with hurricanes forming in the IAS are very low. This may reflect the warm water distribution of the AWP. It is generally considered that tropical waters at least warmer than $26^{\circ}-27^{\circ} \mathrm{C}$ favor the development of largescale convection and are necessary for hurricane development (Gray 1968). Because the IAS always has warm climatological SSTs throughout the hurricane season, a larger or smaller warm pool will not greatly affect SSTs in that region of formation. Thus, we do not expect the warm pool to have a strong effect on hurricanes forming in the IAS. Second, the correlations of the AWP index with hurricanes forming in the early season (JJ) are also very low. This is consistent with the fact that few hurricanes form in the early season and those that do are usually formed in the IAS. Third, the AWP shows significant correlations (above the 95\% significant level) with the hurricanes forming in the TNA region and in midseason. Fourth, the fact that the AWP 

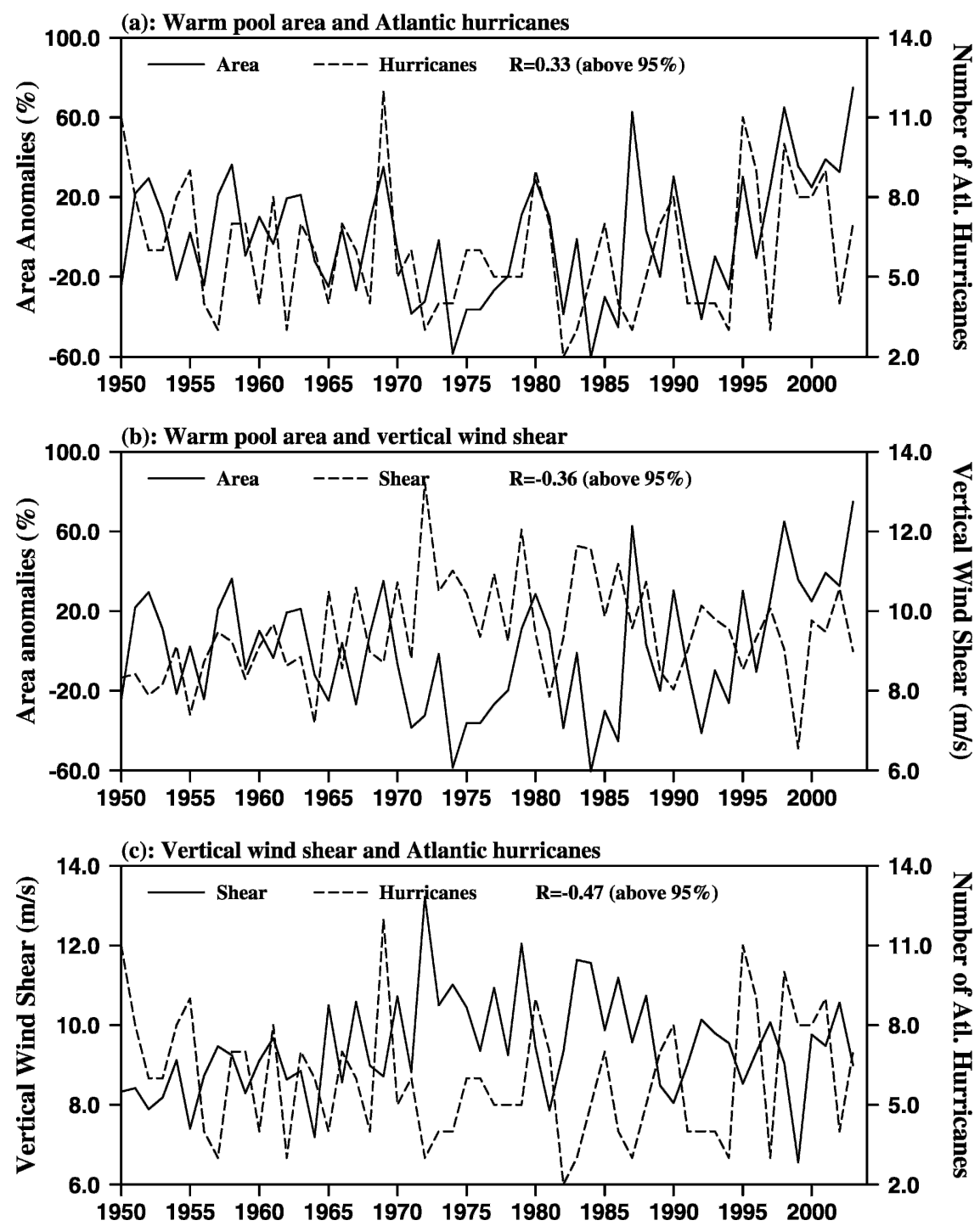

FIG. 11. (a) ASO AWP area anomalies and the total number of Atlantic hurricanes, (b) ASO AWP area anomalies and the vertical wind shear between the upper $(200 \mathrm{mb})$ and lower $(850 \mathrm{mb})$ troposphere in the IAS region $\left(10^{\circ}-25^{\circ} \mathrm{N}, 85^{\circ}-50^{\circ} \mathrm{W}\right)$ during ASO, and (c) the ASO IAS vertical wind shear and the total number of Atlantic hurricanes. The $\mathrm{R}$ represents the correlation coefficient at zero lag.

is significantly correlated with all Atlantic hurricanes testifies to the strength of the relationship in those groups where it is significant, as well as to their numerical dominance in the season totals. We also perform the partial correlation analysis for Table 2. After removing the JJ TNA SST anomalies, the correlation between the JJ AWP area index and hurricanes forming in midseason (AS) is still above the $95 \%$ significant level. However, if we remove the influence of the JJ AWP, the correlation between the JJ TNA SST anomalies and midseason hurricanes is nearly zero. This suggests that hurricanes forming in the midseason are more depen- dent on the JJ AWP than the JJ TNA. The physical basis for this dependence needs to be further investigated.

Another statistical method that can be applied to detect the association between the AWP and hurricanes is the contingency table. Table 3 shows a three by three contingency table for all Atlantic hurricanes and the AWP. All hurricanes are divided into terciles, with the upper (lower) tercile representing active (inactive) hurricane years (18 yr each). Similarly, large (small) warm pool years are ones within the top (bottom) third when ranked by warm pool size. The joint years are then found and filled for each cell. The $\chi^{2}$ test of significance 
TABLE 1. Comparison of the mean hurricane number per year for large and small Atlantic warm pools. A warm pool 25\% larger (smaller) than the climatological area is identified as a large (small) warm pool (see section 3 ). Hurricanes are classified as 1 ) forming in the IAS, 2) forming in the TNA, 3) categories 1-2, 4) categories $3-5,5$ ) forming in early season (JJ), 6) forming in middle season (AS), and 7) forming in late season (ON). Change in percent is calculated as the hurricane number difference between large and small warm pools divided by the hurricane number for small warm pools. Differences significant above the $95 \%$ level are in bold.

\begin{tabular}{lcccc}
\hline \hline & $\begin{array}{c}\text { Large } \\
\text { warm } \\
\text { Hurricane class }\end{array}$ & $\begin{array}{c}\text { Small } \\
\text { warm } \\
\text { pool }\end{array}$ & $\begin{array}{c}\text { Change } \\
(\%)\end{array}$ & $\begin{array}{c}\text { Significance } \\
\text { level (\%) }\end{array}$ \\
\hline Form in IAS & 1.8 & 1.3 & 38 & 76.8 \\
Form in TNA & $\mathbf{3 . 9}$ & $\mathbf{2 . 1}$ & $\mathbf{8 6}$ & $\mathbf{9 9 . 9}$ \\
All categories 1-2 & 4.6 & 3.5 & 31 & 94.3 \\
All categories 3-5 & $\mathbf{2 . 9}$ & $\mathbf{1 . 6}$ & $\mathbf{8 1}$ & $\mathbf{9 9 . 8}$ \\
Form in early season & 0.6 & 0.3 & 100 & 64.0 \\
Form in midseason & $\mathbf{4 . 9}$ & $\mathbf{3 . 5}$ & $\mathbf{4 0}$ & $\mathbf{9 8 . 9}$ \\
Form in late season & $\mathbf{2 . 0}$ & $\mathbf{1 . 2}$ & $\mathbf{6 7}$ & $\mathbf{9 5 . 6}$ \\
All hurricanes & $\mathbf{7 . 5}$ & $\mathbf{5 . 1}$ & $\mathbf{4 7}$ & $\mathbf{9 9 . 9}$ \\
\hline
\end{tabular}

for this table is above the $95 \%$ significance level. For the 54 years from 1950 to 2003, only 2 of the 18 years with small warm pools are active hurricane years, while 11 of the 18 years with large warm pools are active years. Similarly, 4 of the 18 years with large warm pools are inactive years and 8 of the 18 years with small warm pools are inactive years. Again, it shows that large (small) AWPs favor (disfavor) Atlantic hurricanes.

\section{Summary and discussion}

The Central America landmass divides the Western Hemisphere warm pool (WHWP) into two parts: the eastern North Pacific warm pool and the Atlantic warm pool (AWP) that peak around May and September, respectively. Since the eastern North Pacific warm pool is close to the ENSO region of maximum variance, it is directly related to ENSO variability. ENSO affects the tropical Atlantic Ocean via ENSO teleconnections, or atmospheric bridges. However, if an AWP 25\% larger (smaller) than its climatological size is defined as a large (small) AWP, about two-thirds of AWP events occur without preceding winter ENSO events in the Pacific. Despite the geographical difference between the AWP and tropical North Atlantic (TNA), the AWP size is correlated with the TNA SST anomalies. The AWP shows a large anomalous variation, with large warm pools being almost three times larger than small ones.

The atmosphere responds to the total, rather than to the anomalous, SST. Thus, in the region of the warm pool (as in the Indo-Pacific warm pool), a small SST anomaly change can produce a relatively large atmospheric response. During the boreal summer, either in the development/decay phases of ENSO or in neutral conditions, equatorial eastern/central Pacific SST anomalies are relatively weak. However, the AWP reaches its maximum size during that time and thus affects rainfall variability in the Western Hemisphere. The large AWP and warm TNA are found to be positively correlated with rainfall over the northern Caribbean, southern Mexico and Central America, the subtropical North Atlantic, and the southeast Pacific and negatively correlated over the northwest U.S. and Great Plains regions and eastern South America. To separate the impacts of the TNA and ENSO from those of the AWP, we perform partial correlation analyses by removing the TNA SST anomalies or the Niño-3 SST anomalies. Our analyses show that rainfall variability in the Caribbean, Central America, and eastern South America is mainly related to the size of the AWP. The rainfall relationship in the region surrounding the AWP is consistent with oceanic and atmospheric conditions observed over the warm pool region. The warm SST anomalies in the AWP are associated with a decrease in sea level pressure and an anomalous increase in atmospheric convection and cloudiness. Years with a large warm pool have lower sea level pressure and tropospheric vertical wind shear, greater moist instability over the region of the AWP, and a weakened tropical upper-tropospheric trough (Knaff 1997). These conditions lead to more contemporaneous summer rainfall over the region surrounding the warm pool and an increase in tropical cyclone activity.

The AWP serves as a source of moisture for rainfall in North America. If more (less) moisture precipitates over the warm pool, it seems plausible that less (more) would be available for transport into the Great Plains region. This is indeed true for our rainfall correlation map that shows an opposite correlation pattern between the Great Plains and the AWP region. The AWP-related rainfall over the Great Plains region is also consistent with the distribution of surface wind. During ASO, the atmospheric surface wind flows from the AWP to the Great Plains, suggesting the moisture transport from the AWP for rainfall over the Great Plains. As the AWP becomes large (small) and the TNA is warm (cold), the northward wind from the AWP to the Great Plains is weakened (strengthened). This will decrease (increase) the moisture transport available for rainfall over the Great Plains and thus result in decreased (increased) rainfall there.

The AWP also shows a positive rainfall correlation 
(a) 14 Large Warm Pools

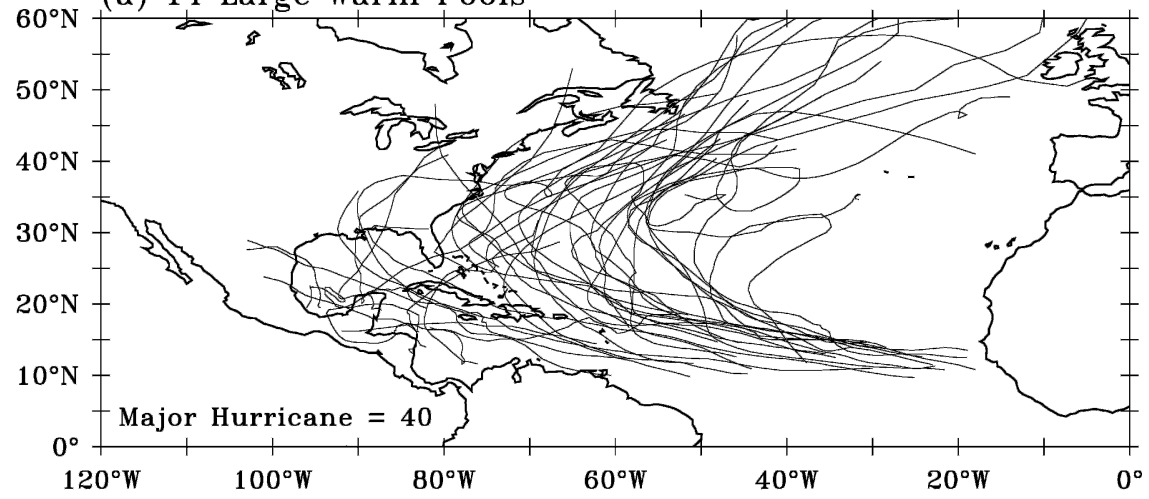

(b) 15 Small Warm Pools

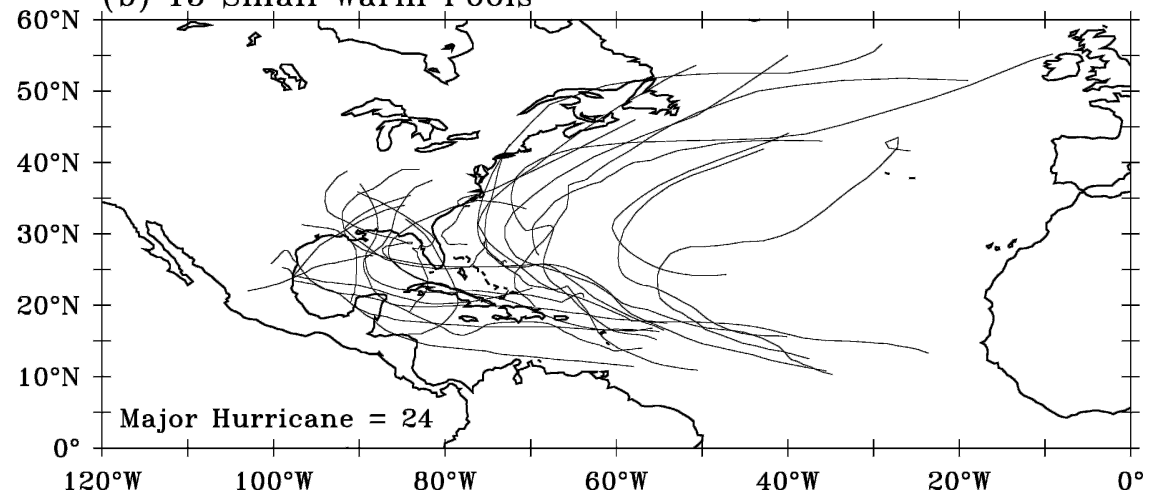

FIG. 12. Atlantic major hurricane tracks for (a) 14 years of large Atlantic warm pools and (b) 15 years of small Atlantic warm pools.

over the southeast Pacific where drizzle under the stratus cloud deck usually appears. Our analyses show that ENSO and local SST anomalies in the southeast Pacific have little or nothing to do with the positive correlation.

TABLE 2. Linear correlation coefficients $(R)$ and significance level (Sig in \%) for eight hurricane classes (rows) vs the JJ, AS, and ON AWP area indices. Hurricanes are classified as 1) forming in the IAS, 2) forming in the TNA, 3) categories 1-2, 4) categories $3-5,5)$ forming in early season (JJ), 6) forming in middle season (AS), and 7) forming in late season (ON). The correlation above the $95 \%$ significant level is in bold.

\begin{tabular}{lrcl}
\hline \hline & \multicolumn{3}{c}{$R(\mathrm{Sig})$} \\
\cline { 2 - 4 } \multicolumn{1}{c}{ Hurricane class } & $\begin{array}{c}\text { JJ warm } \\
\text { pool index }\end{array}$ & $\begin{array}{c}\text { AS warm } \\
\text { pool index }\end{array}$ & $\begin{array}{c}\text { ON warm } \\
\text { pool index }\end{array}$ \\
\hline Form in IAS & $0.14(68.3)$ & $0.14(69.0)$ & $0.00(0.8)$ \\
Form in TNA & $\mathbf{0 . 3 0 ( 9 7 . 4 )}$ & $\mathbf{0 . 3 2}(\mathbf{9 8 . 3 )}$ & $\mathbf{0 . 3 4}(\mathbf{9 8 . 9 )}$ \\
All categories 1-2 & $0.25(93.1)$ & $0.24(92.5)$ & $0.23(91.0)$ \\
All categories 3-5 & $0.21(87.3)$ & $0.26(94.3)$ & $0.17(78.9)$ \\
Form in early season & $-0.09(46.3)$ & $0.03(14.4)$ & $0.06(30.8)$ \\
Form in midseason & $\mathbf{0 . 3 4}(\mathbf{9 8 . 8})$ & $\mathbf{0 . 2 9}(\mathbf{9 6 . 4 )}$ & $\mathbf{0 . 2 9}(\mathbf{9 6 . 5 )}$ \\
Form in late season & $0.19(82.1)$ & $0.24(92.0)$ & $0.08(45.9)$ \\
All hurricanes & $\mathbf{0 . 3 3 ( 9 8 . 4 )}$ & $\mathbf{0 . 3 6}(\mathbf{9 9 . 2 )}$ & $\mathbf{0 . 2 9}(\mathbf{9 6 . 7 )}$ \\
\hline
\end{tabular}

A possible link between the AWP and the southeast Pacific is the regional Atlantic Hadley circulation. Large (small) AWPs strengthen (weaken) the summer Hadley circulation that emanates from the region of the warm pool into the southeast Pacific. This will change the subsidence over the southeast Pacific and thus the stratus cloud and drizzle.

Current rainfall prediction for the WH largely depends on the ENSO condition in the Pacific. The present study and others show that, in addition to ENSO, other climate phenomena like the tropical Atlantic meridional gradient variability, the AWP, the Atlantic Niño, and the Atlantic multidecadal oscillation

TABLE 3. Contingency table for all Atlantic hurricanes vs the AS AWP. The $\chi^{2}$ value is 10.7 and its significance level is $97.0 \%$.

\begin{tabular}{lcccc}
\hline \hline Warm pool & Inactive & Neutral & Active & Total \\
\hline Small & 8 & 8 & 2 & 18 \\
Neutral & 6 & 7 & 5 & 18 \\
Large & 4 & 3 & 11 & 18 \\
Total & 18 & 18 & 18 & 54 \\
\hline
\end{tabular}


also affect WH rainfall distributions. Future rainfall forecasts should consider these additional factors.

Our statistical analysis shows that large AWPs are associated with greater Atlantic hurricane activity. The relationship may be discussed from two points of view: 1) hurricane continued development or intensification and 2) formation of Atlantic hurricanes. From the point of view of the hurricane development/intensification, the AWP is related to hurricane activity because the upper-ocean temperature partly determines the maximum potential development of hurricanes and because warm pool characteristics are correlated with changes in vertical wind shear, known to affect development. Within the warm pool, the temperatures required for development extend to greater depth than elsewhere, thus reducing the tendency of a storm to diminish that potential by mixing cool subsurface water into the upper warm layer. Hence, the size of the warm pool is important because it affects the area over which the intensity and heat content required for sustained development are available. As a storm passes over the warm pool, it will be intensified or further developed. The calculations show that warm water corresponds to a decrease in sea level pressure anomalies and an increase in deep convective activity and atmospheric cloudiness. This is associated with weak tropospheric vertical wind shear and can strengthen the tropical cyclone by helping the organization of deep convection and thus increase Atlantic hurricane activity.

The AWP may also relate to Atlantic hurricane activity through the hurricane formation region. Our rainfall correlation maps show that the AWP and TNA have a positive correlation off West Africa extending westward and covering the tropical eastern north Atlantic. This is the region where easterly waves frequently become hurricanes, which then propagate westward toward the Caribbean and North America. Increased rainfall in this region is indicative of more convection and greater atmospheric instability, which favors cyclogenesis and thus is associated with greater Atlantic hurricane activity. Further studies (in particular, numerical modeling studies) are needed to investigate physical mechanisms regarding the relationships among the AWP, the TNA, rainfall, and Atlantic hurricane activity.

Acknowledgments. We thank three anonymous reviewers and the editor (Sumant Nigam) for comments and suggestions that helped improve the manuscript. This work was supported by a grant from the National Oceanic and Atmospheric Administration (NOAA) Office of Global Programs and by the base funding of the NOAA/Atlantic Oceanographic and Meteorologi- cal Laboratory (AOML). The findings and conclusions in this report are those of the author(s) and do not necessarily represent the views of the funding agency.

\section{REFERENCES}

Adler, R. F., and Coauthors, 2003: The Version-2 Global Precipitation Climatology Project (GPCP) monthly precipitation analysis (1979-present). J. Hydrometeor., 4, 1147-1167.

Alexander, M. A., N.-C. Lau, and J. D. Scott, 2004: Broadening the atmospheric bridge paradigm: ENSO teleconnections to the tropical west Pacific-Indian Oceans over the seasonal cycle and to the North Pacific in summer. Earth's Climate: The Ocean-Atmosphere Interaction, Geophys. Monogr., Vol. 147, Amer. Geophys. Union, 85-104.

Bender, M. A., and I. Ginis, 2000: Real-case simulations of hurricane-ocean interaction using a high-resolution coupled model: Effects on hurricane intensity. Mon. Wea. Rev., 128, 917-946.

Bosilovich, M. G., and S. D. Schubert, 2001: Precipitation recycling in the GEOS-1 data assimilation system over the central United States. J. Hydrometeor., 2, 26-35.

— , and —-, 2002: Water vapor tracers as diagnostics of the regional hydrologic cycle. J. Hydrometeor., 3, 149-165.

Chen, A. A., and M. A. Taylor, 2002: Investigating the link between early season Caribbean rainfall and the El Niño +1 year. Int. J. Climatol., 22, 87-106.

Chiang, J. C. H., and A. H. Sobel, 2002: Tropical tropospheric temperature variations caused by ENSO and their infleunce on the remote tropical climate. J. Climate, 15, 2616-2631.

_- Y. Kushnir, and A. Giannini, 2002: Deconstructing Atlantic Intertropical Convergence Zone variability: Influence of the local cross-equatorial sea surface temperature gradient and remote forcing from the eastern equatorial Pacific. J. Geophys. Res., 107, 4004, doi:10.1029/2000JD000307.

Diaz, H. F., M. P. Hoerling, and J. K. Eischeid, 2001: ENSO variability, teleconnections and climate change. Int. J. Climatol., 21, 1845-1862.

Dommenget, D., and M. Latif, 2000: Interannual to decadal variability in the tropical Atlantic. J. Climate, 13, 777-792.

Enfield, D. B., 1996: Relationships of inter-American rainfall to tropical Atlantic and Pacific SST variability. Geophys. Res. Lett., 23, 3305-3308.

— perature variability and its relation to El Niño-Southern Oscillation. J. Geophys. Res., 102, 929-945.

_ , and E. J. Alfaro, 1999: The dependence of Caribbean rainfall on the interaction of the tropical Atlantic and Pacific Oceans. J. Climate, 12, 2093-2103.

—_, and A. M. Mestas-Nuñez, 1999: Multiscale variabilities in global sea surface temperatures and their relationships with tropospheric climate patterns. J. Climate, 12, 2719-2733.

,$- \ldots$, D. A. Mayer, and L. Cid-Serrano, 1999: How ubiquitous is the dipole relationship in tropical Atlantic sea surface temperatures? J. Geophys. Res., 104, 7841-7848.

$\longrightarrow,-$, and P. J. Trimble, 2001: The Atlantic Multidecadal Oscillation and its relationship to rainfall and river flows in the continental U.S. Geophys. Res. Lett., 28, 2077-2080.

Folland, C. K., T. N. Palmer, and D. E. Parker, 1986: Sahel rainfall and worldwide sea temperatures, 1901-1985. Nature, 320, 602-607.

Giannini, A., Y. Kushnir, and M. A. Cane, 2000: Interannual vari- 
ability of Caribbean rainfall, ENSO, and the Atlantic Ocean. J. Climate, 13, 297-311.

Goldenberg, S. B., C. W. Landsea, A. M. Mestas-Nuñez, and W. M. Gray, 2001: The recent increase in Atlantic hurricane activity: Causes and implications. Science, 293, 474-479.

Gray, W. M., 1968: Global view of the origins of tropical disturbances and storms. Mon. Wea. Rev., 96, 669-700.

, 1979: Hurricanes: Their formation, structure, and likely role in the tropical circulation. Meteorology over the Tropical Oceans, D. B. Shaw, Ed., Royal Meteorological Society, 155218

_ 1984: Atlantic seasonal hurricane frequency. Part I: El Niño and $30 \mathrm{mb}$ quasi-biennial oscillation influences. Mon. Wea. Rev., 112, 1649-1668.

_- 1990: Strong association between West African rainfall and U.S. landfall of intense hurricanes. Science, 249, 1251-1256.

— , J. D. Sheaffer, and C. W. Landsea, 1997: Climate trends associated with multidecadal variability of Atlantic hurricane activity. Hurricanes, Climate and Socioeconomic Impacts, $\mathrm{H}$. F. Diaz and R. S. Pulwarty, Eds., Springer, 15-53.

Houghton, R. W., and Y. M. Tourre, 1992: Characteristics of lowfrequency sea surface temperature fluctuations in the tropical Atlantic. J. Climate, 5, 765-771.

Hu, Q., and S. Feng, 2001: Climate role of the southerly flow from the Gulf of Mexico in interannual variations in summer rainfall in the central United States. J. Climate, 14, 3156-3170.

Jarvinen, B. R., C. J. Neumann, and M. A. S. Davis, 1984: A tropical cyclone data tape for the North Atlantic Basin, 18861983: Contents, limitations, and uses. NOAA Tech. Memo. NWS NHC 22, Coral Gables, FL, 21 pp.

Kalnay, E., and Coauthors, 1996: The NCEP/NCAR 40-Year Reanalysis Project. Bull. Amer. Meteor. Soc., 77, 437-471.

Kerr, R. A., 2000: A North Atlantic climate pacemaker for the centuries. Science, 288, 1984-1986.

Knaff, J. A., 1997: Implications of summertime sea level pressure anomalies in the tropical Atlantic region. J. Climate, 10, 789804.

Landsea, C. W., R. A. Pielke, A. M. Mestas-Nunez, and J. A. Knaff, 1999: Atlantic basin hurricanes: Indices of climatic changes. Climate Change, 42, 89-129.

— , and Coauthors, 2004: The Atlantic hurricane database reanalysis project: Documentation for the 1851-1910 alterations and additions to the HURDAT database. Hurricanes and Typhoons: Past, Present and Future, R. J. Murname and K.-B. Liu, Eds., Columbia University Press, 177-221

Magaña, V., J. A. Amador, and S. Medina, 1999: The midsummer drought over Mexico and central America. J. Climate, 12, $1577-1588$.

Mehta, V. M., 1998: Variability of the tropical ocean surface temperatures at decadal multidecadal timescales. Part I: The Atlantic Ocean. J. Climate, 11, 2351-2375.

Melice, J.-L., and J. Servain, 2003: The tropical Atlantic meridional SST gradient index and its relationships with the SOI, NAO and Southern Ocean. Climate Dyn., 20, 447-464.

Mestas-Nuñez, A. M., and D. B. Enfield, 1999: Rotated global modes of non-ENSO sea surface temperature variability. $J$. Climate, 12, 2734-2746.

Mo, K. C., and R. W. Higgins, 1996: Large-scale atmospheric water vapor transport as evaluated from the NCEP/NCAR and the NASA/DOA reanalyses. J. Climate, 9, 1531-1545.
Molinari, R. L., and A. Mestas-Nunez, 2003: North Atlantic decadal variability and the formation of tropical storms and hurricanes. Geophys. Res. Lett., 30, 1541, doi:10.1029/ 2002GL016462.

Moura, A. D., and J. Shukla, 1981: On the dynamics of droughts in northeast Brazil: Observations, theory and numerical experiments with a general circulation model. J. Atmos. Sci., 38, 2653-2675.

Neelin, J. D., C. Chou, and H. Su, 2003: Tropical drought regions in global warming and El Niño teleconnections. Geophys. Res. Lett., 30, 2275, doi:10.1029/2003GL018625.

Neumann, C. J., B. R. Jarvinen, C. J. McAdie, and G. R. Hammer, 1999: Tropical cyclones of the North Atlantic Ocean, 1871-1999. Historical Climatology Series 6-2, NOAA/NWS/ NESDIS, $206 \mathrm{pp}$.

Philander, S. G. H., D. Gu, G. Lambert, T. Li, D. Halpern, N.-C. Lau, and R. C. Pacanowski, 1996: Why the ITCZ is mostly north of the equator. J. Climate, 9, 2958-2972.

Raper, S., 1992: Observational data on the relationships between climate change and the frequency and magnitude of severe tropical storms. Climate and Sea Level Change: Observations, Projections and Implications, R. A. Warrick, E. M. Barrow, and T. M. L. Wigley, Eds., Cambridge University Press, 192 212.

Rasmusson, E. M., and J. M. Wallace, 1983: Meteorological aspects of the El Niño/Southern Oscillation. Science, 222, 11951202.

Ropelewski, C. F., and M. S. Halpert, 1987: Global and regional precipitation patterns associated with the El Niño/Southern Oscillation. Mon. Wea. Rev., 115, 1606-1626.

—, and - 1989: Precipitation patterns associated with the high index phase of the Southern Oscillation. J. Climate, 2, 268-284.

Saunders, M. A., and A. R. Harris, 1997: Statistical evidence links exceptional 1995 Atlantic hurricane season to record sea warming. Geophys. Res. Lett., 24, 1255-1258.

Sciremammano, F., 1979: A suggestion for the presentation of correlations and their significance levels. J. Phys. Oceanogr., 9, 1273-1276.

Shapiro, L. J., and S. B. Goldenberg, 1998: Atlantic sea surface temperatures and tropical cyclone formation. J. Climate, 11, 578-590.

Shay, L. K., G. J. Goni, and P. G. Black, 2000: Effects of a warm oceanic feature on Hurricane Opal. Mon. Wea. Rev., 128, $1366-1383$.

Smith, T. M., and R. W. Reynolds, 2004: Improved extended reconstruction of SST (1854-1997). J. Climate, 17, 2466-2477.

Spence, J. M., M. A. Taylor, and A. Chen, 2004: The effect of concurrent sea-surface temperature anomalies in the tropical Pacific and Atlantic on Caribbean rainfall. Int. J. Climatol., 24, 1531-1541.

Taylor, M. A., D. B. Enfield, and A. A. Chen, 2002: Influence of the tropical Atlantic versus the tropical Pacific on Caribbean rainfall. J. Geophys. Res., 107, 3127, doi:10.1029/ 2001JC001097.

Wang, C., 2002: Atlantic climate variability and its associated atmospheric circulation cells. J. Climate, 15, 1516-1536.

_ 2005: ENSO, Atlantic climate variability, and the Walker and Hadley circulations. The Hadley Circulation: Past, Present, and Future, H. F. Diaz and R. S. Bradley, Eds., Kluwer Academic, 173-202.

, and D. B. Enfield, 2001: The tropical Western Hemisphere warm pool. Geophys. Res. Lett., 28, 1635-1638. 
— and - 2003: A further study of the tropical Western Hemisphere warm pool. J. Climate, 16, 1476-1493.

Wang, Y., S.-P. Xie, H. Xu, and B. Wang, 2004: Regional model simulations of marine boundary layer clouds over the southeast Pacific off South America. Part I: Control experiment. Mon. Wea. Rev., 132, 274-296.

Webster, P. J., and R. Lukas, 1992: TOGA COARE: The Coupled Ocean-Atmosphere Response Experiment. Bull. Amer. Meteor. Soc., 73, 1377-1416.

Wonnacott, T. H., and R. J. Wonnacott, 1986: Regression: A Second Course in Statistics. Robert E. Krieger Publishing Company, $556 \mathrm{pp}$.
Xie, P., and P. A. Arkin, 1997: Global precipitation: A 17-year monthly analysis based on gauge observations, satellite estimates, and numerical model outputs. Bull. Amer. Meteor. Soc., 78, 2539-2558.

Xie, S.-P., and J. A. Carton, 2004: Tropical Atlantic variability: Patterns, mechanisms, and impacts. Earth's Climate: The Ocean-Atmosphere Interaction, Geophys. Monogr., Vol. 147, Amer. Geophys. Union, 121-142.

Yin, X., A. Gruber, and P. Arkin, 2004: Comparison of the GPCP and CMAP merged gauge-satellite monthly precipitation products for the period 1979-2001. J. Hydrometeor., 5, 12071222 